\title{
Corresponding Member of the Russian Academy of Sciences Valerii Petrovich Kazakov (1934-2010)
}

DOI: $10.1134 / \mathrm{S} 1066362210060196$

Valerii Petrovich Kazakov (1934-2010), corresponding member of the Russian Academy of Sciences, doctor of chemical sciences, honored scientist of the Bashkir ASSR, passed away. Kazakov's labor activity is associated with the Academy of Sciences. After graduation from the Leningrad University in 1957 with radiochemistry specialty, he worked at the Joint Radiocarbon Laboratory of the Leningrad Branch of the Institute of Archeology and Khlopin Radium Institute of the USSR Academy of Sciences, being engaged in recording of extremely small amounts of ${ }^{14} \mathrm{C}$. In 1960, Kazakov left for Akademgorodok (district of academic institutions) in Novosibirsk, where he worked at the Institute of Inorganic Chemistry and Institute of Thermal Physics of the Siberian Branch of the USSR Academy of Sciences. In 1968, Kazakov left for Ufa. Since 1970, he headed the Laboratory of Chemical Physics of the Institute of Organic Chemistry of the Bashkir Branch of the USSR Academy of Sciences, and in 1987-1993 he was vice chairman of the Presidium of the Ufa Scientific Center of the USSR (Russian) Academy of Sciences.

Kazakov's scientific interests were mainly associated with the chemistry of electronically excited atoms and molecules. In 1965, Kazakov discovered the chemiluminescence in reactions of uranium compounds. Under his guidance, efficient luminescence methods were developed for determination of ultralow concentrations of uranium, and solid-state reactions of uranyl compounds with xenon compounds were studied for the first time. Studies in this fruitful direction are continued today. Kazakov initiated studies that led to the discovery of curium chemiluminescence (Frumkin Institute of Physical Chemistry and Electro-

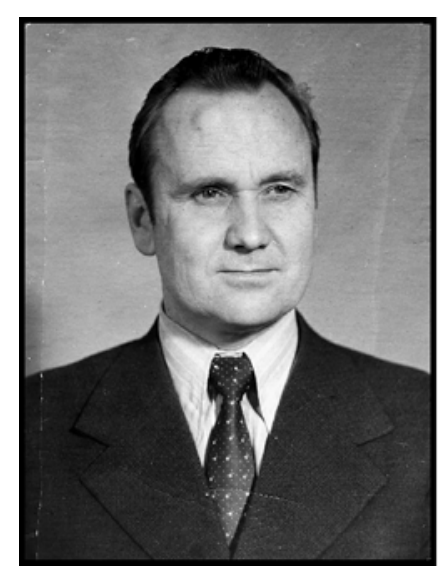

chemistry, Russian Academy of Sciences). Kazakov developed the first aqueous scintillator for the detection of transuranium elements and, in cooperation with researchers from the Kurchatov Institute of Atomic Energy, an antineutrino detector for remote diagnostics of the fuel burn-up in a nuclear reactor.

Kazakov published about 500 scientific works, including six monographs. Six doctors and 25 candidates of sciences have been trained under his guidance. He was the member of the editorial boards of Khimicheskaya fizika (Chemical Physics) and Khimiya vysokikh energii (High Energy Chemistry) journals. He was awarded with the Order for Services to Motherland of Rank II.

Kazakov was an exacting but very benevolent leader, a brilliant teacher. Fond memory of him will live in our hearts. 